\title{
OPENNESS AND THE OUTPUT-INFLATION TRADEOFF: FLOATING VS. FIXED EXCHANGE RATES*
}

\author{
CHI-WA YUEN \\ Peking University and Wuhan University**
}

\begin{abstract}
The paper is an attempt to understand how globalization (in the form of opening up an otherwise closed economy to commodity trade and foreign investment) would interact with the exchange rate regime chosen by a small open economy to determine its output-inflation tradeoff. Based on the stochastic dynamic Mundell-Fleming model, our theory suggests that, under "normal" circumstances, the Phillips curve would be flatter under a fixed exchange rate regime. We also provide some empirical support based on Hong Kong data. [E3; F3]
\end{abstract}

\section{INTRODUCTION}

The possible tradeoff between stimulating output and/or reducing unemployment on the one hand and curbing inflation on the other has been a long recognized problem in the design of macroeconomic stabilization policies. The relation governing this tradeoff has popularly been coined the "Phillips curve." Under the current trend of globalization when countries around the world could interact more closely with one another through trade and capital flows, the nature of the output-inflation tradeoff could be very different from that in a closed economy. This is because in an open economy, external (in addition to internal) factors can also affect both national output and domestic inflation. The result is a change in the slope of the Phillips curve. Since the Phillips curve can be conceived of as a policy constraint in the government's stabilization problem, the change in slope would imply a change in the nature of stabilization policies as well.

Despite the trend towards increasing integration of the world economy through liberalization of both the current and capital accounts, much of the theoretical analysis of the Phillips curve has been confined to closed economy contexts. In

*This is a revised version of the paper I presented at the 3rd IEJ Economics Annual at Seoul University on October 26, 2001. Helpful comments from Noh-Sun Kwark, Adrian Pagan, Wooheon Rhee, and other conference participants as well as financial support from the Hong Kong RGC are gratefully acknowledged. The usual disclaimer applies.

${ }^{* *}$ On leave from the University of Hong Kong. 
open economies, one important factor that may affect the inflation-unemployment tradeoff is the degree of capital mobility. In the context of the Mundell-Fleming (ad hoc Keynesian) model, Loungani, Razin, and Yuen (2001) have shown that, due to the opposite effects of the domestic interest rate and the real exchange rate, capital mobility will have, in general, an ambiguous effect on the output-inflation tradeoff. But the parameter estimates of Papell (1988) suggest that the realexchange-rate effect would dominate the interest-rate effect to induce a steeper Phillips curve under capital controls. ${ }^{1}$ This result has been reaffirmed by Razin and Yuen (2002) in the context of the Woodford-Obstfeld-Rogoff optimizationbased new open-economy macroeconomic (New Keynesian) model, where consumption smoothing, which comes with the opening of the capital market, will raise the degree of strategic complementarity among monopolistically competitive suppliers of goods, thus rendering prices more sticky and magnifying the output responses to nominal shocks to generate a flatter Phillips curve. ${ }^{2}$ Empirical support for this relation between capital mobility and the output-inflation tradeoff is provided by Loungani, Razin, and Yuen $(2001,2002)$, who find that countries that impose greater restrictions on capital mobility do tend to have steeper Phillips curves and lower sacrifice ratios.

Another, no less important factor that may affect the output-inflation tradeoff in the open economy is the choice of exchange rate regimes. Flood and Marion (1982), for instance, show how a change in the exchange rate system will alter the degree of international transmission of disturbances through a change in the expectations formed by rational agents in the asset market and consequently a change in the slope of the aggregate supply curve (an analog of the Phillips curve). But they do not indicate exactly how the slope varies across exchange rate

\footnotetext{
${ }^{1}$ Under capital controls, the interest-rate effect arises because interest rate parity will not hold, so that more room is left for the domestic interest rate to adjust to shocks. On the other hand, the real-exchange-rate effect arises because the zero net-trade-balance restriction (when the capital account is closed) will limit the flexibility of the real exchange rate. These two opposing effects on aggregate demand also account for the changing slopes of the Phillips curve under different degrees of capital mobility.

${ }^{2}$ Capital-account openness would stabilize consumption, and marginal utility, fluctuations. This will rigidify adjustments in the reservation wage. Thus given a shock, the flex-price firms will adjust their prices by less than otherwise. This implies that the fix-price firms will have to adjust quantity of labor, hence output, by more than otherwise. This is why the Phillips curve is flattened.

Conversely, we also show how shutting down trade altogether will further steepen the Phillips curve relative to closing the capital account only. Trade openness has a disciplinary effect on the flex-price firms. Given a negative (inflationary) shock, in the presence of international competition, the flex-price firms will adjust their prices by less than otherwise. This implies that the shock will take away from (or add to, in the case it is a positive /deflationary shock) the demand faced by the fix-price firms, thus resulting in a larger output gap and a flatter Phillips curve.
} 
regimes. $^{3}$ DiNardo and Moore (1999), on the other hand, have extended empirically the Phillips curve to an open economy using a market-based and observable measure of inflation expectations, and shown how supply shocks as well as changing inflation expectations were equally responsible for the empirical failure of the Phillips curve in the 1970s. But they do not address the role of exchange rate regime on the slope of the Phillips curve either. A more relevant paper for our purpose is Ghironi-Giavazzi (2000). They consider how the size of the country may affect the employment-inflation tradeoff under different exchange rate regimes and, on this basis, how the optimal size of a currency area can be determined.

Instead of worrying about the role of country size, we shall focus on a small open economy and examine how the choice of exchange rate regimes may affect the slope of the Phillips curve. The rest of the paper is organized as follows. Section 2 presents a theoretical analysis of the relation between two polar exchange rate regimes on the one hand and the output-inflation tradeoff on the other. Some preliminary evidence based on data from Hong Kong (a small open economy) during two different exchange rate periods is reported in Section 3. Section 4 concludes and suggests directions for future research. A brief review of the historical development of the Phillips curve is contained in Appendix I.

\section{THEORY BASED ON THE STOCHASTIC DYNAMIC MUNDELL- FLEMING MODEL}

Consider a stochastic dynamic version of the Mundell-Fleming model. Such a framework assumes a set of exogenous stochastic processes (e.g., money supply) which drives the dynamics of the equilibrium system. Since economic agents are forward-looking, each short-run equilibrium is based on expectations about future shocks and the resulting future short-run equilibria.

For simplicity, we express all variables in logarithmic forms (except for the interest rates) and assume all behavioral relations are linear in these log variables. This linear system can be viewed as an approximation from an original nonlinear system.

Aggregate demand in period $t, y_{t}^{d}$, specified as a function of an exogenous demand component, $d_{t}$, the domestic real rate of interest, $r_{t}$, and the real exchange

\footnotetext{
${ }^{3}$ Alogoskoufis and Smith (1991) have proposed, tested, and failed to reject the hypothesis that higher exchange-rate accommodation would increase the persistence of inflation differentials among countries, which are also reflected in expectations-augmented Phillips curves. Like Flood and Marion (1982), however, they do not specify a precise exchange ratePhillips curve relation. To make it even worse, their hypothesis has recently been proven by Kool and Lammertsma (2000) as analytically incorrect. In particular, they show that the derivative of relative inflation persistence with respect to the degree of exchange rate accommodation is, in general, ambiguous.
} 
rate, $q_{t}$, is given by

$$
y_{t}^{d}=d_{t}-\sigma r_{t}+\eta q_{t},
$$

where $\sigma$ and $\eta$ are positive elasticities. The real variables $r_{t}$ and $q_{t}$ are derived from the following nominal variables: $i_{t}$, the domestic nominal rate of interest; $p_{t}$, the domestic price level; $p^{*}$, the foreign price level (assumed for simplicity to be constant over time); and $s_{t}$, the spot exchange rate (the domestic currency value of foreign currency). More specifically, $r_{t}=i_{t}-E_{t}\left(p_{t+1}-p_{t}\right)$ and $q_{t}=s_{t}+p^{*} p_{t}$.

Aggregate demand is positively related to the exogenous demand shock, capturing external, fiscal, and other internal shocks. The real interest rate affects negatively aggregate demand by discouraging investment and consumption. The real exchange rate affects positively aggregate demand by stimulating the traded sector (exportables and domestic production of importables).

Money market equilibrium is specified as:

$$
m_{t}-p_{t}=y_{t}-\lambda i_{t}
$$

where $m_{t}$ is the money supply at time $t$, and $\lambda(>0)$ the interest semi-elasticity of the demand for money. As usual, domestic output/income $\left(y_{t}\right)$ has a positive effect on money demand, while the domestic nominal rate of interest $\left(i_{t}\right)$ has a negative effect. To simplify matters, the income elasticity is assumed to be unity.

Price setting is based on a mix of auction markets and long-term contract markets. The market-clearing price in the auction market is $p_{t}^{e}$. The price in the long-term contract market is set one period in advance according to expectations of the future market-clearing price in that market, $E_{t-1} p_{t}^{e}$. Accordingly, the general price level in the domestic economy, $p_{t}$, is given by a weighted average of these two prices:

$$
p_{t}=\theta p_{t}^{e}+(1-\theta) E_{t-1} p_{t}^{e},
$$

where $\theta(\in[0,1])$ is the share of the auction market in domestic output. The longterm contract element is akin to Taylor (1981) and Fischer (1981). This introduces an element of price rigidity into the system.

Under free capital mobility, interest parity prevails. Assuming risk neutrality, uncovered interest parity should hold, i.e.,

$$
i_{t}=i^{*}+E_{t}\left(s_{t+1}-s_{t}\right),
$$


where $i^{*}$ is the world rate of interest, assumed for simplicity to be constant over time. Through costless arbitrage, the return on investing one unit of domestic currency in domestic security, $i_{t}$, is made equal to the expected value of the domestic currency return on investing the same amount in foreign security, which yields a foreign currency return, $i^{*}$, plus an expected depreciation of domestic currency, $E_{t}\left(s_{t+1}-s_{t}\right)$

The equilibrium system consists of the four equations (1)-(4) at each point in time. The shock processes that drive the dynamics of the equilibrium system are:

$$
\begin{aligned}
& y_{t}^{s}=g_{y}+y_{t-1}^{s}+\varepsilon_{y_{t}}, \\
& d_{t}=g_{y}+d_{t-1}+\varepsilon_{d_{t}}, \\
& m_{t}=g_{m}+m_{t-1}+\varepsilon_{m_{t}},
\end{aligned}
$$

where $g_{y}$ and $g_{m}$ are the deterministic growth rates of output and money, and $\varepsilon_{y_{t}}, \varepsilon_{d_{t}}, \varepsilon_{m_{t}}$ are independently and identically distributed (i.i.d.) supply, demand, and money shocks with zero means and constant variances. ${ }^{4}$ Accordingly, our specification assumes that the system is bombarded by permanent shocks in a random walk fashion.

Note that although equation (5a) indicates that the supply of natural output is exogenously given (so that the aggregate supply curve is vertical), equilibrium output is demand-determined under sticky prices. This explains why the output gap (gap between actual and natural output) is not necessarily zero in the fullfledged solution

\section{The Phillips Curve under Flexible and Fixed Exchange Rate Regimes}

Since our framework is both forward- and backward-looking, a systematic procedure is required to obtain a solution. We thus apply a two-stage procedure for solving the equilibrium system (1)-(5). In the first stage, we solve for a flexible price equilibrium that corresponds to this system. In the second stage, we

\footnotetext{
${ }^{4}$ To guarantee the existence of a long-run (steady-state) equilibrium for our system, the deterministic growth rates of output on both the supply and demand sides $\left(g_{y}\right)$ are assumed to be identical.
} 
use the flex-price equilibrium to arrive at a full-fledged solution for the mixed fixflex-price system. [See chapter 4 of Frenkel, Razin, and Yuen (1996) for details.] The same solution procedure is applied to both the flexible and fixed exchange rate scenarios.

\section{A. Flexible Exchange Rates}

Denoting the excess of natural output $y_{t}^{e}$ (i.e., output under the flex-price equilibrium) over and above actual output $y_{t}$ (i.e., output under the full-fledged equilibrium $)^{5}$ by $u_{t}=y_{t}^{e}-y_{t}$, we have an expectations-augmented Phillips curve relation between unanticipated inflation $\left(\pi_{t}-\pi_{t}^{e}\right)$ and the output gap $\left(u_{t}\right)$ as follows:

$$
\pi_{t}-\pi_{t}^{e}=-\left[\frac{\lambda+\sigma+\eta}{(1+\lambda)(\sigma+\eta)}\right] u_{t}
$$

where the superscript ' $e$ ' denotes the flex-price equilibrium and $\pi_{t}^{e}=g_{m}-g_{v}$. Equation (6a) shows that the Phillips curve is flatter when the aggregate demand elasticities $\sigma$ (with respect to the domestic real rate of interest) and $\eta$ (with respect to the real exchange rate) are higher. The effect of the interest semi-elasticity of money demand $(\lambda)$ on the slope of the Phillips curve is, however, ambiguous, depending on whether $\sigma+\eta$ exceeds or falls short of unity. The source of this ambiguity is derived from the more fundamental ambiguity in the effects of excess innovations on the domestic nominal interest rate and spot exchange rates. (See Appendix II for derivation of these results.)

\section{B. Fixed Exchange Rates}

Under the alternative fixed exchange rate system, $s_{t}=\bar{s}$ (some constant target level). If the system is stable and fully credible, then $E_{t}\left(s_{t+1}\right)=s_{t}=\bar{s}$ so that, from equation (4), the uncovered interest parity implies that the domestic nominal interest rate is given by $i_{t}=i^{*}$. The real exchange rate is simply $q_{t}=\bar{s}$ $+p^{*}-p_{t}$.

${ }^{5}$ This excess capacity is obviously positively related to the rate of cyclical unemployment (i.e., the gap between actual and natural unemployment). That is why the expectationsaugmented Phillips curve is sometimes specified as a relation between unanticipated inflation and cyclical unemployment. 
As shown in Appendix II, the Phillips curve now becomes:

$$
\pi_{t}-\pi_{t}^{e}=-\left(\frac{1}{\sigma+\eta}\right) u_{t}
$$

where $\pi_{t}^{e}=0$ in this case. Again, the slope of the Phillips curve is decreasing in the aggregate demand elasticities $\sigma$ and $\eta$.

\section{A comparison}

In summary, the (absolute) slope of the Phillips curve under flexible exchange rates is given by:

$$
\phi^{\text {flex }} \equiv-\left.\frac{d\left(\pi_{t}-\pi_{t}^{e}\right)}{d u_{t}}\right|_{\text {flex }}=\frac{\lambda+\sigma+\eta}{(1+\lambda)(\sigma+\eta)}=\left(\frac{1}{\sigma+\eta}\right)\left(1+\frac{\sigma+\eta-1}{1+\lambda}\right),
$$

whereas the (absolute) slope of the Phillips curve under fixed exchange rates is given by:

$$
\phi^{f i x} \equiv-\left.\frac{d\left(\pi_{t}-\pi_{t}^{e}\right)}{d u_{t}}\right|_{f i x}=\frac{1}{\sigma+\eta}
$$

We can thus conclude that $\phi^{f l e x} \stackrel{>}{=} \phi^{f i x}$ as $\sigma+\eta \stackrel{>}{=} 1.6$

Intuitively, since flexible exchange rates provide an extra degree of freedom to support the adjustment of other prices in buffering the real economy against various shocks, we would expect a given change in unanticipated inflation to be

${ }^{6}$ In the text, we are referring to the tradeoff between the levels of the output gap and unanticipated inflation. In fact, one can also show using the results in Appendix II that the tradeoff between output volatility and inflation volatility—so-called volatility tradeoff that is also popularly discussed in the policy literature-satisfies similar relations. In particular,

$$
\sigma_{\pi}=\phi^{f l e x} \sigma_{u} \text { and } \sigma_{\pi}=\phi^{f f x} \sigma_{u}
$$

under the flexible and fixed exchange rate regimes respectively. In other words, the same slope comparison carries over from the level frontier to the volatility frontier. 
associated with a smaller change in the output gap, i.e., a steeper Phillips curve. The result above indicates, however, that this need not be true if the elasticities of aggregate demand with respect to the domestic real interest rate and the real exchange rate are sufficiently small—so that aggregate demand is not sensitive to price changes anyway..

From the parameter estimates of Papell (1988) summarized in Loungani, Razin, and Yuen (2001), we see that $\sigma+\eta$ is likely to exceed unity (cf. 1.27 in Germany, 0.88 in the US, and 2.56 in Japan). This confirms our intuition-that the Phillips curve would be steeper under the floating rate regime-as a "normal" case.

Note also that while the change in exchange rate regimes will leave the natural output unchanged (given $y_{t}^{e}=y_{t}^{s}$ ), it will alter inflation expectations, with rightside justification $\left(\pi^{e}\right)^{f l e x}=g_{m}-g_{y} \stackrel{>}{=} O=\left(\pi^{e}\right)^{f i x}$ as $g_{m} \stackrel{>}{=} g_{y}$. In the usual case where $g_{m}>g_{y}$, the two Phillips curves will intersect somewhere in the $4^{\text {th }}$ quadrant of the $u-\pi$ plane. Changes in the expected rate of inflation due to permanent changes in the relative money-output growth rates will then shift the Phillips curve around under the floating rate regime, but not also under the alternative fixed rate regime.

\section{SOME EVIDENCE FROM A SMALL OPEN ECONOMY}

As a reflection of the Lucas critique, the choice of exchange rate regimes can affect both inflation expectations and the degree of tradeoff between inflation and output. Since Hong Kong adopted a floating exchange rate regime during the period November 1974-September 1983 and a fixed (so-called "linked") rate regime since October 1983, it provides a natural laboratory for us to empirically examine the exchange rate-Phillips curve relation. In particular, we shall use Hong Kong data to examine how the nature of the output-inflation tradeoff as exemplified by the expectations-augmented Phillips curve may have been altered by a switch from the floating exchange rate regime to the fixed rate regime in 1983.

\section{A. The Data and the Empirical Methodology}

Our price and output data are drawn from the HKSAR government's GDP estimates, 1975-2000. We use the GDP as our measure of nominal output, and the GDP deflator as a measure of the price level. Real output (output at constant 1990 prices) is obtained by dividing nominal GDP by the deflator. The inflation rate is simply the rate of change of the price level, i.e., $\pi_{t}=\left(P_{t} / P_{t-1}\right) \times 100$. All

\footnotetext{
${ }^{7}$ This case $(\sigma+\eta>1)$ nonetheless implies the absence of exchange rate overshooting. Papell (1988) claims, however, that his constrained maximum likelihood method of estimation is much more successful in empirically implementing the Dornbusch model than single equation methods.
} 
computations and statistical analysis in the remainder of this paper are based on the inflation and real output data so constructed.

From our theory, the expectations-augmented Phillips curve can be stated as follows:

$$
\pi_{t}-\pi_{t}^{e}=-\phi u_{t}, \phi>0,
$$

where $\pi_{t}$ and $\pi_{t}^{e}$ are the actual and expected rates of inflation at time $t, u_{t}$ the output gap at time $t$, and $\phi$ the (absolute) slope of the Phillips curve respectively. The simple Phillips curve is just a special case with $\pi_{t}^{e}=0$.

Equation (6) suggests the following form of a regression equation:

$$
\pi_{t}=\beta_{0}+\beta_{l} u_{t}+\varepsilon_{t},
$$

where $\beta_{0}$ is the intercept, and $\beta_{l}$ the slope, of the Phillips curve, and $\varepsilon$ the residual errors. Comparing equations (6) and (7), we have

$$
\beta_{0}=\pi_{t}^{e} \text { and } \beta_{l}=\phi .
$$

Our theory in the previous section suggests that, due to changing inflationary expectations and the changing tradeoff between inflation and output under different exchange rate arrangements, $\beta_{0}$ and $\beta_{l}$ will vary across exchange rate systems. In the "normal" (intuitive) case, our null hypotheses are that $\beta_{1}^{f l e x}>\beta_{1}^{f i x}$ and $\beta_{0}^{f l e x}>\beta_{0}^{f i x}$.

To implement a test of these hypotheses, a measure of excess capacity, $u_{t}$, is required. We shall measure $u_{t}$ by the logarithm of detrended output, i.e., deviation of actual log output from its growth trend. Suppose output grows continuously at the long-run constant rate $g$, then $y_{t}=y_{0} \cdot \exp (g t)$, implying that $\ln \left(y_{t}\right)=\ln \left(y_{0}\right)+g t$. The $(\log )$ linear trend can thus be fitted by running the following regression: $\ln \left(y_{t}\right)=\alpha_{0}+\alpha_{1} t+u_{t}$, where $\alpha_{0}$ and $\alpha_{l}$ are estimates of $\ln \left(y_{0}\right)$ and $g$, and the residual $u_{t}$ the deviation of $\ln \left(y_{t}\right)$ from trend-is precisely our measure of excess capacity. This completes the description of our method of constructing $u_{t}$.

We are now ready to use the regression equation (7) to examine how the Phillips curve depends on the choice of exchange rate regimes. Three sets of regression are run for the following time periods: 1975-1982, 1984-1996, and 1975-1996. The rationale behind our choice of time periods lies in the historical development of the exchange rate system in HK. Following the abandonment of the Sterling Exchange Standard and subsequently the US dollar peg, Hong Kong 
entered an era of floating exchange rate in November 1974. The system lasted until October 1983 when, being shaken up by the confidence crisis prior to the Sino-British Agreement of 1984, it was replaced by the Linked Exchange Rate. This is still the system we have in place, even after the handover of sovereignty from the British to the Chinese in 1997. This explains why we divide the period 1975-1996 into two sub-periods: 1975-82 (the floating rate period) and 19841996 (the fixed rate period), after dropping the interim years, 1974 and 1983, which were "contaminated" by the mixture of the two exchange rate regimes. We have also thrown out the more recent 1997-2001 period as there were credibility problems during and after the speculative attack on the HK dollar in October/November 1997 and August 1998. ${ }^{8}$

\section{B. The Findings, Plausible Interpretations, and Policy Implications}

Table 1 provides measures of the average levels and variability (in terms of both standard deviations and coefficients of variations) of inflation and output in Hong Kong. Owing perhaps to the insulating property of fixed exchange rates, inflation was more volatile in the floating rate than in the fixed rate period while output volatility was about the same in both periods. For sure, these differences could also reflect changes in the economic environment (e.g., nature of economic shocks) in addition to changes in the exchange rate regime across the two periods.

Table 1. Summary Statistics of Inflation and Output in Hong Kong

\begin{tabular}{lccc}
\hline & Floating ER (1976-82) & Fixed ER (1985-96) & Whole period (1975-2000) \\
\hline average inflation & 10.58 & 7.53 & 6.84 \\
inflation variability & 4.28 & 2.64 & 5.20 \\
average output growth & 8.89 & 5.63 & 6.10 \\
variability of detrended output & 0.022 & 0.033 & 0.083 \\
\hline
\end{tabular}

Three Phillips curves are estimated based on the regression equation (7), and least square estimates of their intercepts and slopes are summarized in Table 2. The Phillips curve under the floating rate regime has a bigger intercept and slope than its fixed rate counterpart. ${ }^{9}$ In other words, in the case of Hong Kong, the expected rate of inflation was found to be higher under the floating rate system, and the cost of output expansion in terms of (unanticipated) inflation was found to be smaller under the fixed rate system.

\footnotetext{
${ }^{8}$ Recall that our theory assumes that the fixed exchange rate system is fully credible.

${ }^{9}$ The slope estimate under the floating rate period is not significant, though.
} 
Table 2. The Phillips Curve in Hong Kong

\begin{tabular}{lccc}
\hline & Floating ER (1976-82) & Fixed ER (1985-96) & Whole period (1975-2000) \\
\hline intercept & $10.58(1.75)$ & $7.53(0.62)$ & $6.84(0.85)$ \\
slope & $75.86(80.74)$ & $53.80(18.89)$ & $37.54(10.25)$ \\
\hline
\end{tabular}

Note: Standard errors of the parameter estimates are given in parentheses.

In order to scrutinize more rigorously whether the intercept and slope parameters are significantly different under the two regimes, we have also conducted tests of structural change by running three additional sets of restricted regressions: (i) intercept parameters are restricted to be regime-invariant, (ii) slope parameters are restricted to be regime-invariant, and (iii) both intercept and slope parameters are restricted to be regime-invariant. The results are compared to those from the unrestricted regression to form an F-test of whether the intercept and slope parameters vary across exchange rate regimes. The test shows that although we can reject the hypothesis that all (both the intercept and slope) parameters are the same across the two regimes at the 5\% level, we cannot reject it at the $1 \%$ level. Neither can we reject the hypotheses that the intercept (slope) parameters are the same, given the slope (intercept) parameters are the same, across the two regimes. In this sense, the evidence is not clear enough for us to draw a definite conclusion. Given the relatively short data series and the low goodness-of-fit, a more rigorous study using more sophisticated econometric techniques and longer data series from other countries is nonetheless called for.

In any case, can some policy implications be drawn from such results? Hardly, for at least two reasons. First of all, our empirical methodology assumes implicitly that the Phillips curves we have estimated for the two exchange rate regimes are stable. In particular, expected inflation rates are restricted to be constant across time although they can vary across exchange rate systems. In reality, inflationary expectations may be affected by other economic or political factors in addition to exchange rate regimes. On the other hand, changes in the natural output over time may also alter the growth trend from which detrended output deviates. This is especially relevant to the current situation in Hong Kong, given the rise in structural unemployment due largely to sectoral shifts and the relocation of manufacturing plants to South China in the past decade. Obviously, time-variations in the expected inflation rate and/or natural output can shift the expectations-augmented Phillips curve around. In other words, what we have traced are possibly inflation-output pairs from many (instead of a single) short-run Phillips curves. This is the infamous "identification problem" in econometrics. In order to identify the Phillips curve, a complete structural model that includes specification of the inflation expectations-formation process and the determination of the natural rate/output is necessary. Policy-wise, the inflation-output tradeoff we 
obtain from our regression analysis is not an easily exploitable one, given the Phillips curve is unstable.

Second, even when the Phillips curve is stable, the inflation-output tradeoff may still not be a very useful one for policy makers. One has to remember that the curve is merely an ex post statistical relation. Familiar arguments from the Mundell-Fleming model tell us that the effectiveness of government policies in regulating output can be limited by the choice of exchange rate regime: In the presence of free capital mobility, monetary policy is totally ineffective under fixed exchange rate while fiscal policy becomes ineffective under the floating rate. As mentioned above, one will also lose control over inflation when monetary policy is to target the exchange rate, as under the fixed rate.

In fact, the active non-intervention philosophy of the Hong Kong government during the period of study suggests that, even if the tradeoff were stable, it would not have been exploited to fine-tune the economy. On the one hand, its conservative, surplus-prone budgetary policy has been designed more for revenueraising than discretionary purpose. On the other hand, its strict adherence to the linked exchange rate system has made its monetary policy completely passive and accommodating (i.e., its money supply becomes essentially endogenous).

\section{CONCLUSION}

The objective of this paper is to understand how globalization (in the form of opening up an otherwise closed economy to commodity trade and foreign investment) would interact with the exchange rate regime chosen by a small open economy to determine its output-inflation tradeoff.

Based on the stochastic dynamic Mundell-Fleming model, our theory suggests that, under "normal" circumstances, the Phillips curve would be flatter under a fixed exchange rate regime. Our preliminary empirical finding based on Hong Kong data also provides some support for this result.

A lot of room remains for improvement of our analysis. A list of the possible extensions in three alternative directions follows. All these issues are left for future research.

\section{A. Theoretical Extensions}

- Embedding New Keynesian microfoundations along the lines of Obstfeld and Rogoff (1996), Woodford (2002), and Razin and Yuen (2001). (Among other things, this will make aggregate supply endogenous.)

- Comparison with open-economy extension of the New Classical model with imperfect/asymmetric information. 
- "Large" (instead of small) open economies.

- Different assumptions about the statistical properties of the shocks. For instance, what if the supply, demand, and monetary shocks contain both transitory and permanent components and/or are correlated with one another?

\section{B. Empirical Extensions}

- Incorporating the pre-1974 (sterling peg) period? Using quarterly (instead of annual) data?

- Data from other countries operating under fixed and flexible exchange rate systems..

- More rigorous econometric analysis. For instance,

- using other detrending methods or estimates of natural output to obtain a more accurate measure of the output gap;

- allowing for time-varying coefficients as estimates of changing inflation expectations or introducing other assumptions to obtain a more accurate measure of expected (hence, unanticipated) inflation;

- adding instrumental variables to dodge the endogeneity bias; and/or

- estimating the entire (simultaneous equation) model (including $\eta$ and $\sigma$ ) by maximum likelihood.

- A more fair assessment of macroeconomic effects of exchange rate arrangements by conducting some counter-factual simulations that involve estimating the shocks that affected the economy in one exchange rate period and artificially imposing them on the economy in another exchange rate period (see, e.g., Kwan and Lui 1999)

\section{Policy Implications}

- What are the implications of the changing slopes of the Phillips curve for

- the optimal design of monetary and fiscal policy (in stabilizing inflation and output) in the open economy?

- the optimal choice of exchange rate arrangements?

- the optimal degree of trade-account openness and capital-account openness? 


\section{APPENDIX I}

\section{A Brief History of the Phillips Curve}

First discovered by Fisher (1926) and later rediscovered by Phillips (1958), the term "Phillips curve" refers to the negative correlation between inflation and unemployment. Academics notwithstanding, this empirical regularity is especially appealing to policymakers as it is believed to offer an exploitable tradeoff between two important macro policy targets and a useful tool for inflation forecasting. [See Atkeson and Ohanian (2001).]

Such tradeoff, the so-called simple Phillips curve, was nonetheless proven by the theoretical contributions of Friedman (1968) and Phelps (1968) in the late 1960s and the observed phenomenon of stagflation in the 1970s to be an unstable and unreliable one. Since you may fool all of the people some of the time and some of the people all of the time, a tradeoff may still exist in the short run between unanticipated (i.e., difference between actual and expected) inflation and cyclical (i.e., difference between actual and natural) unemployment. This tradeoff will, however, vanish in the long run or may not even exist in any case if people form inflation expectations rationally (because you cannot fool all of the people all of the time). In other words, the inflation-unemployment relation is better described by the expectations-augmented Phillips curve.

Up to the mid-1980s, as McCallum (1990) summarizes, there were at least 4 basic types of Phillips curve or aggregate supply theories, viz., (i) the New Classical flexible price, monetary misperceptions theories [Lucas (1972)], (ii) the New Keynesian sticky price theories [Fischer (1977), Ball, Mankiw, and Romer (1988)], (iii) the "non-accelerating-inflation rate of unemployment" (NAIRU) theories [Tobin (1980)], and (iv) the "reverse causation" result of real business cycle (RBC) theories, which maintain that there is no such relation as a Phillips curve [King and Plosser (1984)]. Empirical tests have nonetheless failed to deliver clear-cut conclusions as to which is a better theory of the Phillips curve [see, e.g., Barro (1978), Mishkin (1982), King and Watson (1994), and Roberts (1995)].

More recently, reflecting on the current understanding about the inflationunemployment tradeoff, Mankiw (2000) has described it as "inexorable" and "mysterious", and identified the resolution of the inconsistency between standard models of inflation-unemployment dynamics on the one hand and conventional views about the effects of monetary policy on the other as a prominent outstanding puzzle for business cycle theorists. The sustained interest of the profession on the subject of the output-inflation tradeoff has been further witnessed by the publication of a special issue on "The Return of the Phillips Curve" in the Journal of Monetary Economics (1999) as well as the symposium on "The Natural Rate of Unemployment" in the Journal of Economic Perspectives (1997). Among other things, people nowadays are most concerned about the time-varying NAIRU and 
its implications for the instability of the Phillips curve and thus the exploitability of the inflation-output tradeoff by policymakers for their design of stabilization policies. For one, Sargent (1999) has shown how policymakers in the US increased inflation in the 1960s by following erroneous assumptions about the exploitability of the Phillips curve.

Every now and then, new ideas and/or terminologies get attached to the subject, ranging from inflation persistence [Fuhrer and Moore (1995)], to the relation of the output-inflation tradeoffs to sticky information [Mankiw and Reis (2001)] and productivity growth [Ball and Moffitt (2001)], to nonlinear [Laxton, Rose, and Tambakis (1999)] and sunspot [Chichilnisky, Heal, and Lin (1995)] Phillips curves - to name just a few examples. However, the analysis of these papers as well as the ones mentioned above is largely confined to closed economy contexts. Analysis of the Phillips curve in open economy settings is summarized in the introductory section of this paper.

Last but not least, there are two strands of the literature that are closely related to our paper. The first is about the slope of the Phillips curve. The second is about the implications of the Phillips curve for monetary policy rules. Among examples of the former, Lucas (1973) conjectures and confirms empirically that countries with higher variability in nominal GNP growth will have steeper Phillips curves, while BallMankiw-Romer (1988) show that a higher mean inflation rate will produce similar slope effects. Examples of the latter include Cecchetti and Ehrmann (1999), Clark, Goodhart, and Huang (1999), Dittmar and Gavin (2000), and Kiley (1998). These papers are mainly concerned about the implications of alternative versions of the Phillips curve (say, New Classical vs. New Keynesian) for the usefulness of inflation targeting and other monetary targeting rules in controlling inflation and output volatilities. [See also Svensson (2000) for an open-economy analysis.] In so doing, they have also highlighted another, related tradeoff, i.e., that between inflation variability and output variability. [See also Walsh (1999).]

\section{APPENDIX II}

\section{Derivation of the Full-Fledged Solution and the Phillips Curve}

\section{A. Flexible Exchange Rates Solution}

Using the superscript ' $e$ ' to denote the flex-price equilibrium, the first-stage solution can be determined as follows.

- When prices are perfectly flexible and the supply of goods is exogenous, output must be supply-determined, hence $y_{t}^{e}=y_{t}^{s}$.

- With constant money demand elasticities, the expected rate of inflation (which turns out also to be the actual inflation rate) must be equal to the difference 
between money growth and output growth, hence $\pi_{t}^{e}=g_{m}-g_{y}$.

- Since world prices are constant in the foreign country (hence zero world inflation), both the real and nominal world rates of interest must be equal to $i^{*}$.

- Under free capital mobility, the domestic real rate of interest must be equal to $i^{*}$ as well, i.e., $r_{t}^{e}=i^{*}$.

- The Fisher equation linking the nominal rate of interest to the real rate and the expected rate of inflation then implies $i_{t}^{e}=i^{*}+g_{m}-g_{y}$.

- Given the domestic real interest rate, the real exchange rate that equates output demand to the exogenous supply of output can be solved from the aggregate demand equation as $q_{t}^{e}=\frac{1}{\eta}\left(y_{t}^{s}-d_{t}+\sigma i^{*}\right)$.

- Given the domestic nominal rate of interest and output, the domestic price level consistent with money market equilibrium is $p_{t}^{e}=m_{t}-y_{t}^{s}+\lambda\left(i^{*}+g_{m}-g_{y}\right)$.

- Finally, we can derive the nominal exchange rate from the definition of the real exchange rate as $s_{t}^{e}=q_{t}^{e}+p_{t}^{e}-p^{*}=m_{t}+\left(\frac{l}{\eta}-1\right) y_{t}^{s}-\left(\frac{l}{\eta}\right) d_{t}+\left(\frac{\sigma}{\eta}+\lambda\right) i^{*}-p^{*}+\lambda\left(\varepsilon_{m_{t}}-\varepsilon_{y_{t}}\right)$.

Given the flex-price equilibrium, the full-fledged equilibrium (second-stage solution) can be found as follows.

Derivation of $p_{t}$.

$$
\begin{aligned}
p_{t}= & \theta p_{t}^{e}+(1-\theta) E_{t-1}\left(p_{t}^{e}\right) \\
= & \theta\left[m_{t}-y_{t}^{s}+\lambda\left(i^{*}+g_{m}-g_{y}\right)\right] \\
& +(1-\theta)[\underbrace{\left(g_{m}+m_{t-1}\right)}_{m_{t}-\varepsilon_{m_{t}}}-\underbrace{\left(g_{y}+y_{t-1}^{s}\right)}_{y_{t}^{s}-\varepsilon_{y_{t}}}+\lambda\left(i^{*}+g_{m}-g_{y}\right)] \\
= & p_{t}^{e}-(1-\theta)\left(\varepsilon_{m_{t}}-\varepsilon_{y_{t}}\right) .
\end{aligned}
$$

Derivation of $\pi_{t}$.

$$
\begin{aligned}
\pi_{t} & =E_{t}\left(p_{t+1}-p_{t}\right)=E_{t}\left(p_{t+1}^{e}-p_{t}^{e}\right)+(1-\theta)\left(\varepsilon_{m_{t}}-\varepsilon_{y_{t}}\right) \\
& =\pi_{t}^{e}+(1-\theta)\left(\varepsilon_{m_{t}}-\varepsilon_{y_{t}}\right) .
\end{aligned}
$$


Derivation of $q_{t}$.

$$
\begin{aligned}
\eta\left(q_{t}-q_{t}^{e}\right)= & \left(y_{t}-y_{t}^{e}\right)+\sigma\left(r_{t}-r_{t}^{e}\right), \text { given } y_{t}=d_{t}+\eta q_{t}-\sigma r_{t} \\
= & -\left(p_{t}-p_{t}^{e}\right)+\lambda\left(i_{t}-i_{t}^{e}\right)+\sigma\left(r_{t}-r_{t}^{e}\right) \\
& \text { using the money market equilibrium condition } \\
= & (\lambda+\sigma) E_{t}\left[\left(q_{t+1}-q_{t+1}^{e}\right)-\left(q_{t}-q_{t}^{e}\right)\right] \\
& +(1+\lambda)(1-\theta)\left(\varepsilon_{m_{t}}-\varepsilon_{y_{t}}\right)
\end{aligned}
$$

since $E_{t}\left(q_{t+1}^{e}\right)=\frac{I}{\eta}\left(y_{t}^{s}-d_{t}+\sigma i^{*}\right)=q_{t}^{e}$,

$$
\begin{aligned}
i_{t}-i_{t}^{e} & =\left[i^{*}+E_{t}\left(s_{t+1}-s_{t}\right)\right]-\left(i^{*}+g_{m}-g_{y}\right) \\
& =E_{t}\left[\left(q_{t+1}+p_{t+1}-p^{*}\right)-\left(q_{t}+p_{t}-p^{*}\right)\right]-\left(g_{m}-g_{y}\right) \\
& =E_{t}\left(q_{t+1}-q_{t}\right)+(1-\theta)\left(\varepsilon_{m_{t}}-\varepsilon_{y_{t}}\right), \text { and } \\
r_{t}-r_{t}^{e} & =\left[i_{t}-E_{t}\left(p_{t+1}-p_{t}\right)\right]-\left[i_{t}^{e}-E_{t}\left(p_{t+1}^{e}-p_{t}^{e}\right)\right] \\
& =\left(i_{t}-i_{t}^{e}\right)-(1-\theta)\left(\varepsilon_{m_{t}}-\varepsilon_{y_{t}}\right) \\
& =E_{t}\left(q_{t+1}-q_{t}\right) .
\end{aligned}
$$

If we guess solution of the form $q_{t}=q_{t}^{e}+\kappa\left(\varepsilon_{m_{t}}-\varepsilon_{v_{t}}\right)$ and substitute it into the $\eta\left(q_{t}-q_{t}^{e}\right)$ equation above, we can solve for $\kappa=(1+\lambda)(1-\theta) /(\lambda+\sigma+\eta)$. Hence the solution for the real exchange rate is given by:

$$
q_{t}=q_{t}^{e}+\left(\frac{1+\lambda}{\lambda+\sigma+\eta}\right)(1-\theta)\left(\varepsilon_{m_{t}}-\varepsilon_{y_{t}}\right) .
$$

so that $E_{t}\left(q_{t+1}-q_{t}\right)=-\left(\frac{1+\lambda}{\lambda+\sigma+\eta}\right)(1-\theta)\left(\varepsilon_{m_{t}}-\varepsilon_{y_{t}}\right)$, 
Derivation of $i_{t}$.

$$
\begin{aligned}
i_{t}-i_{t}^{e} & =E_{t}\left(q_{t+1}-q_{t}\right)+(1-\theta)\left(\varepsilon_{m_{t}}-\varepsilon_{y_{t}}\right) \\
& =\left(\frac{\sigma+\eta-1}{\lambda+\sigma+\eta}\right)(1-\theta)\left(\varepsilon_{m_{t}}-\varepsilon_{y_{t}}\right) .
\end{aligned}
$$

Derivation of $r_{t}$.

$$
\begin{aligned}
r_{t} & =r_{t}^{e}+E_{t}\left(q_{t+1}-q_{t}\right) \\
& =r_{t}^{e}-\left(\frac{1+\lambda}{\lambda+\sigma+\eta}\right)(1-\theta)\left(\varepsilon_{m_{t}}-\varepsilon_{y_{t}}\right) .
\end{aligned}
$$

Derivation of $s_{t}$.

$$
\begin{aligned}
s_{t}-s_{t}^{e} & =\left(q_{t}-q_{t}^{e}\right)+\left(p_{t}-p_{t}^{e}\right)-\left(p^{*}-p^{*}\right) \\
& =-\left(\frac{\sigma+\eta-1}{\lambda+\sigma+\eta}\right)(1-\theta)\left(\varepsilon_{m_{t}}-\varepsilon_{y_{t}}\right) .
\end{aligned}
$$

Derivation of $y_{t}$.

$$
\begin{aligned}
y_{t}-y_{t}^{e} & =\left(d_{t}-d_{t}^{e}\right)+\eta\left(q_{t}-q_{t}^{e}\right)-\sigma\left(r_{t}-r_{t}^{e}\right) \\
& =\left[\frac{(\sigma+\eta)(1+\lambda)}{\lambda+\sigma+\eta}\right](1-\theta)\left(\varepsilon_{m_{t}}-\varepsilon_{y_{t}}\right) .
\end{aligned}
$$

In summary, the full-fledged solution can be stated as: 


$$
p_{t}=p_{t}^{e}-(1-\theta)\left(\varepsilon_{m_{t}}-\varepsilon_{y_{t}}\right),
$$

where $p_{t}^{e}=m_{t}-y_{t}^{s}+\lambda\left(i^{*}+g_{m}-g_{y}\right)$;

$$
\pi_{t}=\pi_{t}^{e}+(1-\theta)\left(\varepsilon_{m_{t}}-\varepsilon_{y_{t}}\right),
$$

where $\pi_{t}^{e}=g_{m}-g_{y}$;

$$
q_{t}=q_{t}^{e}+\left(\frac{1+\lambda}{\lambda+\sigma+\eta}\right)(1-\theta)\left(\varepsilon_{m_{t}}-\varepsilon_{y_{t}}\right)
$$

where $q_{t}^{e}=\frac{1}{\eta}\left(y_{t}^{s}-d_{t}+\sigma i^{*}\right)$;

$$
i_{t}=i_{t}^{e}+\left(\frac{\sigma+\eta-1}{\lambda+\sigma+\eta}\right)(1-\theta)\left(\varepsilon_{m_{t}}-\varepsilon_{y_{t}}\right)
$$

where $i_{t}^{e}=i^{*}+g_{m}-g_{y}$;

$$
r_{t}=r_{t}^{e}-\left(\frac{1+\lambda}{\lambda+\sigma+\eta}\right)(1-\theta)\left(\varepsilon_{m_{t}}-\varepsilon_{y_{t}}\right)
$$

where $r_{t}^{e}=i^{*}$

$$
s_{t}=s_{t}^{e}-\left(\frac{\sigma+\eta-1}{\lambda+\sigma+\eta}\right)(1-\theta)\left(\varepsilon_{m_{t}}-\varepsilon_{y_{t}}\right)
$$

where $s_{t}^{e}=m_{t}+\left(\frac{1}{\eta}-1\right) y_{t}^{s}-\left(\frac{1}{\eta}\right) d_{t}+\left(\frac{\sigma}{\eta}+\lambda\right) i^{*}-p^{*}+\lambda\left(\varepsilon_{m_{t}}-\varepsilon_{y_{t}}\right)$; and 


$$
y_{t}=y_{t}^{e}+\left[\frac{(\sigma+\eta)(1+\lambda)}{\lambda+\sigma+\eta}\right](1-\theta)\left(\varepsilon_{m_{t}}-\varepsilon_{y_{t}}\right) \text {, }
$$

where $y_{t}^{e}=y_{t}^{s}$.

The Phillips curve equation that we stated in the main text for the case of flexible exchange rates — viz., equation (6a) — can be obtained by combining equations (A.2) and (A.7) and noting that excess output capacity, is defined as $u_{t} \equiv-\left(y_{t}-y_{t}^{e}\right)$.

\section{B. Fixed Exchange Rates Solution}

Again, we denote the flex-price equilibrium by the superscript ' $e$ '. The firststage solution can be determined as follows.

- Under perfectly flexible prices and exogenous supply of goods, output is supplydetermined, hence $y_{t}^{e}=y_{t}^{s}$.

- Under fixed exchange rates, $s_{t}=\bar{s}=E_{t}\left(s_{t+1}\right)$, so that $i_{t}=i^{*}$ by uncovered interest parity.

- Since world prices are constant in the foreign country (hence zero world inflation), the world real interest rate must be equal to $i^{*}$. Under free capital mobility, the domestic real rate of interest must be equal to $i^{*}$ as well, i.e., $r_{t}^{e}=i^{*}$.

- Given the domestic real interest rate, the real exchange rate that equates output demand to the exogenous supply of output can be solved from the aggregate demand equation as $q_{t}^{e}=\frac{1}{\eta}\left(y_{t}^{s}-d_{t}+\sigma i^{*}\right)$.

- But since $q_{t}=s_{t}+p^{*}-p_{t}$, we have $p_{t}^{e}=\bar{s}+p^{*}-\frac{1}{\eta}\left(y_{t}^{s}-d_{t}+\sigma i^{*}\right)$, which implies that $\pi_{t}^{e}=E_{t}\left(p_{t+1}^{e}\right)-p_{t}^{e}=0$.

- Finally, the (endogenous) supply of money that satisfies money market equilibrium is given by $m_{t}^{e}=p_{t}^{e}+y_{t}^{e}-\lambda i^{*}$.

Given the flex-price equilibrium, the full-fledged equilibrium (second-stage solution) can be found as follows.

Derivation of $p_{t}$. 


$$
\begin{aligned}
p_{t}= & \theta p_{t}^{e}+(1-\theta) E_{t-1}\left(p_{t}^{e}\right) \\
= & \theta\left[\bar{s}+p^{*}-\frac{1}{\eta}\left(y_{t}^{s}-d_{t}+\sigma i^{*}\right)\right] \\
& +(1-\theta)\left\{\bar{s}+p^{*}-\frac{1}{\eta}\left[\left(y_{t}^{s}-\varepsilon_{y_{t}}\right)-\left(d_{t}-\varepsilon_{d_{t}}\right)+\sigma i^{*}\right]\right\} \\
= & p_{t}^{e}+\left(\frac{1-\theta}{\eta}\right)\left(\varepsilon_{y_{t}}-\varepsilon_{d_{t}}\right) .
\end{aligned}
$$

Derivation of $\pi_{t}$.

$$
\pi_{t}=E_{t}\left(p_{t+1}-p_{t}\right)=\pi_{t}^{e}-\left(\frac{1-\theta}{\eta}\right)\left(\varepsilon_{y_{t}}-\varepsilon_{d_{t}}\right) .
$$

Derivation of $q_{t}$.

$$
\begin{aligned}
q_{t}-q_{t}^{e} & =\left(s_{t}+p^{*}-p_{t}\right)-\left(s_{t}^{e}+p^{*}-p_{t}^{e}\right) \\
& =-\left(\frac{1-\theta}{\eta}\right)\left(\varepsilon_{y_{t}}-\varepsilon_{d_{t}}\right) .
\end{aligned}
$$

Derivation of $i_{t}$.

$$
\begin{aligned}
i_{t}-i_{t}^{e} & =\left[i^{*}+E_{t}\left(s_{t+1}-s_{t}\right)\right]-i^{*} \\
& =0 .
\end{aligned}
$$

Derivation of $r_{t}$. 


$$
\begin{aligned}
r_{t}-r_{t}^{e} & =\left(i_{t}-i_{t}^{e}\right)-\left(\pi_{t}-\pi_{t}^{e}\right) \\
& =\left(\frac{1-\theta}{\eta}\right)\left(\varepsilon_{y_{t}}-\varepsilon_{d_{t}}\right) .
\end{aligned}
$$

Derivation of $y_{t}$.

$$
\begin{aligned}
y_{t}-y_{t}^{e} & =\eta\left(q_{t}-q_{t}^{e}\right)-\sigma\left(r_{t}-r_{t}^{e}\right) \\
& =-\left(1+\frac{\sigma}{\eta}\right)(1-\theta)\left(\varepsilon_{y_{t}}-\varepsilon_{d_{t}}\right)
\end{aligned}
$$

In summary, the full-fledged solution can be stated as:

$$
p_{t}=p_{t}^{e}-\left(\frac{1-\theta}{\eta}\right)\left(\varepsilon_{y_{t}}-\varepsilon_{d_{t}}\right),
$$

where $p_{t}^{e}=\bar{s}+p^{*}-\frac{1}{\eta}\left(y_{t}^{s}-d_{t}+\sigma i^{*}\right)$;

$$
\pi_{t}=\pi_{t}^{e}-\left(\frac{1-\theta}{\eta}\right)\left(\varepsilon_{y_{t}}-\varepsilon_{d_{t}}\right)
$$

where $\pi_{t}^{e}=0$;

$$
q_{t}=q_{t}^{e}-\left(\frac{1-\theta}{\eta}\right)\left(\varepsilon_{y_{t}}-\varepsilon_{d_{t}}\right)
$$

where $q_{t}^{e}=\frac{1}{\eta}\left(y_{t}^{s}-d_{t}+\sigma i^{*}\right) \quad($ as in the floating rate case);

$$
i_{t}=i_{t}^{e}=i^{*}
$$




$$
r_{t}=r_{t}^{e}+\left(\frac{1-\theta}{\eta}\right)\left(\varepsilon_{y_{t}}-\varepsilon_{d_{t}}\right),
$$

where $r_{t}^{e}=i^{*}$ (as in the floating rate case);

$$
s_{t}=s_{t}^{e}=\bar{s} ;
$$

and

$$
y_{t}=y_{t}^{e}-\left(1+\frac{\sigma}{\eta}\right)(1-\theta)\left(\varepsilon_{y_{t}}-\varepsilon_{d_{t}}\right),
$$

where $y_{t}^{e}=y_{t}^{s}$ (as before).

The Phillips curve equation that we stated in the main text for the case of fixed exchange rates-viz., equation (6b) — can be obtained by combining equations (A.2') and (A.7').

\section{REFERENCES}

Alogoskoufis, George S., and Smith, Ron, "The Phillips Curve, the Persistence of Inflation, and the Lucas Critique: Evidence from Exchange Rate Regimes," American Economic Review 81, 1991, 1254-1275.

Atkeson, Andrew, and Ohanian, Lee E., "Are Phillips Curves Useful for Forecasting Inflation?" Federal Reserve Bank of Minneapolis Quarterly Review 25, Winter 2001, 2-11.

Ball, Laurence, Mankiw, N. Gregory, and Romer, David, "The New Keynesian Economics and the Output-Inflation Tradeoff," Brookings Papers on Economic Activity 19, 1988, 1-65.

, and Robert Moffitt, "Productivity Growth and the Phillips Curve," NBER Working Paper No. 8421, August 2001.

Barro, Robert J., "Unanticipated Money, Output, and the Price Level in the United States," Journal of Political Economy 86, 1978, 549-580.

Cecchetti, Stephen G., and Ehrmann, Michael, "Does Inflation Targeting Increase Output Volatility? An International Comparison of Policymakers' Preferences and Outcomes," NBER Working Paper No. 7426, December 1999.

Chichilnisky, Graciela, Heal, Geoffrey, and Lin, Yun, "Chaotic Price Dynamics, Increasing Returns, and the Phillips Curve," Journal of Economic Behavior 
and Organization 27, 1995, 279-291.

Clark, Peter B., Goodhart, Charles A. E., and Huang, Haizhou, "Optimal Monetary Policy Rules in a Rational Expectations Model of the Phillips Curve," Journal of Monetary Economics 43, 1999, 497-520.

DiNardo, John, and Moore, Mark P., "The Phillips Curve is Back? Using Panel Data to Analyze the Relationship between Unemployment and Inflation in an Open Economy," NBER Working Paper, no. 7328, National Bureau of Economic Research, August 1999.

Dittmar, Robert, and Gavin, William T., "What do New-Keynesian Phillips Curve Imply for Price-Level Targeting?" Federal Reserve Bank of St. Louis Review, March/April 2000, 21-30.

Donner, A., and McCallum, J. F., "The Phillips Curve: An Historical Note," Economica 39, 1972, 322-323.

Fischer, Stanley, "Long-term Contracts, Rational Expectations, and the Optimal Money Supply Rule,” Journal of Political Economy 85, 1977, 191-206.

Fisher, Irving, "A Statistical Relation between Unemployment and Price Changes," International Labor Review 13, 1926, 785-792.

Flood, Robert P., and Marion, Nancy P., "The Transmission of Disturbances under Alternative Exchange-Rate Regimes with Optimal Indexing," Quarterly Journal of Economics, 1982, 43-66.

Frenkel, Jacob A., Razin, Assaf, and Yuen, Chi-Wa, Fiscal Policies and Growth in the World Economy, MIT Press, 1996.

Friedman, Milton, "The Role of Monetary Policy," American Economic Review 58, 1968, 1-17.

Fuhrer, J. C. and Moore, G. R., "Inflation Persistence," Quarterly Journal of Economics 110, 1995, 127-159.

Ghironi, Fabio, and Giavazzi, Francesco, "Currency Areas, International Monetary Regimes, and the Employment-Inflation Tradeoff," Journal of International Economics 45, 1998, 259-296.

Gordon, Robert J., "The Time-Varying NAIRU and its Implications for Economic Policy," Journal of Economic Perspectives 11, Winter 1997, 11-32.

"The Phillips Curve Now and Then," in Peter Diamond ed., Growth, Productivity, Unemployment: Essays to Celebrate Bob Solow's Birthday, MIT Press, 1990.

, "Hysteresis in History: Was There Ever a Phillips Curve?" American Economic Review Papers and Proceedings 79, 1989, 220-225.

HKSAR Government, 2001 Gross Domestic Product, Census and Statistics Department, Hong Kong Special Administrative Region, 2002.

Humphrey, Thomas H., From Trade-offs to Policy Ineffectiveness: A History of the Phillips Curve, Federal Reserve Bank of Richmond, October 1986.

Kiley, Michael T., "Monetary Policy under Neoclassical and New-Keynesian Phillips Curve, with an Application to Price Level and Inflation Targeting," unpublished manuscript, Federal Reserve Board, May 1998. 
King, Robert G., and Plosser, Charles I. (eds.), "Special Issue: The Return of the Phillips Curve," Journal of Monetary Economics 44, 1999, 159-336.

"Money, Credit, and Prices in a Real Business Cycle," American Economic Review 74, 1984, 363-380.

, and Watson, Mark W., "The Post-War U.S. Phillips Curve: A

Revisionist Econometric History," Carnegie-Rochester Conference Series on Public Policy 41, 1994, 157-219.

Kool, Clemens J. M., and Lammertsma, Alex, "The Phillips Curve, the Persistence of Inflation, and the Lucas Critique: Evidence from Exchange Rate Regimes: Comment," American Economic Review 90, 2000, 312-315.

Kwan, Yum K., and Lui, Francis T., "Hong Kong's Currency Board and Changing Monetary Regimes," in Takatoshi Ito and Anne O. Krueger eds., Changes in Exchange Rates in Rapidly Developing Countries, NBER-East Asia Seminar on Economics, Volume 7, University of Chicago Press, 1999.

Lane, Philip R., "The New Open Economy Macroeconomics: A Survey," Journal of International Economics 54, 2001, 235-266.

Laxton, Douglas, Rose, David, and Tambakis, Demosthenes, "The US Phillips Curve: The Case for Asymmetry," Journal of Economic Dynamics and Control 23, 1999, 1459-1485.

Loungani, Prakash, Razin, Assaf, and Yuen, Chi-Wa, "Sacrifice Ratios in Closed vs. Open Economies: An Empirical Test," working paper, May 2002. , "Capital Mobility and the Output-Inflation Tradeoff," Journal of Development Economics 64, 2001, 255-274.

Lucas, Robert E., Jr., "Some International Evidence on Output-Inflation Tradeoffs," American Economic Review 63, 1973, 326-334.

, "Expectations and the Neutrality of Money," Journal of Economic Theory 4, 1972, 103-124.

Mankiw, N. Gregory, "The Inexorable and Mysterious Tradeoff between Inflation and Unemployment," NBER Working Paper, no. 7884, National Bureau of Economic Research, September 2000. , and Reis, Ricardo, "Sticky Information vs. Sticky Prices: A Proposal to Replace the New Keynesian Phillips Curve," NBER Working Paper, no. 8290, National Bureau of Economic Research, May 2001.

McCallum, Bennett T., "Inflation: Theory and Evidence," in Benjamin M. Friedman and Frank H. Hahn eds., Handbook of Monetary Economics, volume 2, North-Holland, 1990.

Mishkin, Frederic S. "Does Anticipated Monetary Policy Matter? An Econometric Investigation," Journal of Political Economy 90 1982, 22-51.

Obstfeld, Maurice, and Rogoff, Kenneth, Foundations of International Macroeconomics, MIT Press, 1996.

Papell, David H., "Expectations and Exchange Rate Dynamics after a Decade of Floating," Journal of International Economics 25, 1988, 303-317.

Phelps, Edmund S., "Money Wage Dynamics and Labor Market Equilibrium," 
Journal of Political Economy 76, 1968, 687-711.

Phillips, A. W., "The Relation between Unemployment and the Rate of Change of Money Wage Rates in the United Kingdom, 1896-1957," Economica 25, 1958, 283-299.

Razin, Assaf, and Yuen, Chi-Wa, "The New Keynesian Phillips curve: Closed Economy vs. Open Economy," Economics Letters 75, 2002, 1-9.

Roberts, John M., "New Keynesian Economics and the Phillips Curve," Journal of Money, Credit, and Banking 27, 1995, 975-984.

Romer, David, "Openness and Inflation: Theory and Evidence," Quarterly Journal of Economics, 1993, 869-903.

Sargent, Thomas J., The Conquest of American Inflation, Princeton University Press, 1999.

Svensson, Lars E. O., "Open-Economy Inflation Targeting," Journal of International Economics 50, 2000, 155-183.

Taylor, John B., "Aggregate Dynamics and Staggered Contracts," Journal of Political Economy 88, 1980, 1-23.

Tobin, James, "Stabilization Policy Ten Years After," Brookings Papers on Economic Activity, 1980, 19-71.

Walsh, Carl E., "Monetary Policy Trade-offs in the Open Economy," unpublished manuscript, UC Santa Cruz, November 1999.

Woodford, Michael, "Optimizing Models with Nominal Rigidities," Chapter 3 of Interest and Prices: Foundations of a Theory of Monetary Policy, Princeton University Press, 2002 (forthcoming).

Mailing Address: Professor Chi-Wa Yuen, School of Economics and Finance, University of Hong Kong, Pokfulam, Hong Kong. Tel: (852) 2859-1058, Fax: (852)2548-1152,E-mail: cwyuen@hku.hk 